\title{
ARTICLE
}

\section{Validation of a nicotine vapor self-administration model in rats with relevance to electronic cigarette use}

Lauren C. Smith $\mathbb{D}^{1,2}$, Marsida Kallupi $\mathbb{D}^{1,2}$, Lani Tieu ${ }^{2}$, Kokila Shankar ${ }^{1,2}$, Abigail Jaquish ${ }^{3}$, Jamie Barr ${ }^{3}$, Yujuan Su$^{3}, \mathrm{Nathan}$ Velarde ${ }^{2}$, Sharona Sedighim ${ }^{2}$, Lieselot L. G. Carrette $\mathbb{D D}^{1,2}$, Mike Klodnicki ${ }^{4}$, Xin Sun ${ }^{3}$, Giordano de Guglielmo ${ }^{1,2}$ and Olivier George $\mathbb{D}^{1,2}$

The debate about electronic cigarettes is dividing healthcare professionals, policymakers, manufacturers, and communities. A key limitation in our understanding of the cause and consequences of vaping is the lack of animal models of nicotine vapor selfadministration. Here, we developed a novel model of voluntary electronic cigarette use in rats using operant behavior. We found that rats voluntarily exposed themselves to nicotine vapor to the point of reaching blood nicotine levels that are similar to humans. The level of responding on the active (nicotine) lever was similar to the inactive (air) lever and lower than the active lever that was associated with vehicle (polypropylene glycol/glycerol) vapor, suggesting low positive reinforcing effects and low nicotine vapor discrimination. Lever pressing behavior with nicotine vapor was pharmacologically prevented by the a4 $\beta 2$ nicotinic acetylcholine receptor partial agonist and a7 receptor full agonist varenicline in rats that self-administered nicotine but not vehicle vapor. Moreover, 3 weeks of daily $(1 \mathrm{~h})$ nicotine vapor self-administration produced addiction-like behaviors, including somatic signs of withdrawal, allodynia, anxiety-like behavior, and relapse-like behavior after 3 weeks of abstinence. Finally, 3 weeks of daily ( $1 \mathrm{~h}$ ) nicotine vapor self-administration produced cardiopulmonary abnormalities and changes in $a 4, a 3$, and $\beta 2$ nicotinic acetylcholine receptor subunit mRNA levels in the nucleus accumbens and medial prefrontal cortex. These findings validate a novel animal model of nicotine vapor self-administration in rodents with relevance to electronic cigarette use in humans and highlight the potential addictive properties and harmful effects of chronic nicotine vapor self-administration.

Neuropsychopharmacology (2020) 45:1909-1919; https://doi.org/10.1038/s41386-020-0734-8

\section{INTRODUCTION}

Electronic cigarette use is exponentially increasing worldwide, particularly among adolescents and former smokers [1]. Electronic cigarettes are generally perceived to be safer than traditional cigarettes [2-4] because these devices do not burn tobacco to release nicotine, but instead heat a nicotine solution in the form of "vape juice," "e-juice," or "e-liquid." This liquid typically consists of propylene glycol and glycerin. It is often available in different flavors that appeal to both traditional cigarette smokers and nonsmokers [5]. However, our understanding of this relatively new nicotine delivery system and its long-term effects on human health is incomplete. Some in vitro models suggest that electronic cigarettes are safe $[6,7]$, whereas others suggest that they may be harmful $[8,9]$. Recent studies in human tissue have demonstrated the toxic effects of electronic cigarette components [10-12]. Little in vivo data are available to parse the short- and long-term effects of electronic cigarette use on addiction-like behaviors and pulmonary function [13]. For example, nicotine vapor is assumed to be addictive because nicotine itself is addictive. However, there is no evidence that animals, other than nonhuman primates, will self-administer nicotine vapor to the point of developing addiction-like behaviors. Such information is critical to contribute to the social, political, and medical debate. Healthcare professionals in some countries, such as in the European Union and
Australia, are currently recommending electronic cigarettes as smoking cessation aids [14, 15].

Much of our neurobiological understanding of nicotine use and abuse has been made through preclinical experiments in rats that intravenously self-administer nicotine [16]. Data that are generated by these models improve our understanding of the psychoactive effects of nicotine, but nicotine is administered via other routes of administration. Moreover, data suggest that sensory stimulation through the lungs may contribute to nicotine's addiction potential [17]. Electronic cigarettes do not have the same chemical profile as traditional tobacco cigarettes, but the combustion of electronic cigarette liquid has been found to produce some similar byproducts, such as formaldehyde, carbon monoxide, and hydrocarbons $[18,19]$. Rats that have been made dependent by passive exposure to nicotine vapor exhibit hyperalgesia, somatic signs of withdrawal, and greater motivation to self-administer nicotine intravenously after withdrawal [20, 21]. However, both intravenous and passive vapor models are inadequate to completely understand self-motivated addictionlike behaviors that are associated with electronic cigarette use and the abuse potential of inhaled nicotine vapor.

To date, however, no method has been developed to study the effects of nicotine vapor self-administration in an animal model. Therefore, the present study combined both intravenous nicotine

\footnotetext{
${ }^{1}$ Department of Neuroscience, The Scripps Research Institute, 10550N. Torrey Pines Road, La Jolla, CA, USA; ${ }^{2}$ Department of Psychiatry, School of Medicine, University of California, La Jolla, San Diego, CA, USA; ${ }^{3}$ Department of Pediatrics, University of California, La Jolla, CA, USA and ${ }^{4}$ Gram Research, San Francisco, CA, USA Correspondence: Marsida Kallupi (mkallupi@health.ucsd.edu) or Olivier George (olgeorge@health.ucsd.edu)

These authors contributed equally: Lauren C. Smith, Marsida Kallupi
}

Received: 3 December 2019 Revised: 21 May 2020 Accepted: 1 June 2020

Published online: 16 June 2020 
self-administration and passive nicotine vapor exposure to develop a rat model of nicotine vapor self-administration and provide behavioral, pharmacological, and anatomopathological validation that is relevant to electronic cigarette use in humans.

\section{MATERIALS AND METHODS}

Animals

Fifty-two Wistar rats ( $n=52$ [25 males, 27 females]), weighing 200-220 g (Charles River), were group housed two per cage under a $12 \mathrm{~h} / 12 \mathrm{~h}$ light/dark cycle with ad libitum access to food and water. All of the experiments began $2 \mathrm{~h}$ into the dark cycle. All of the procedures were conducted in accordance with the National Institutes of Health Guide for the Care and Use of Laboratory Animals and approved by The Scripps Research Institute and University of California, San Diego, Institutional Animal Care and Use Committees.

\section{Drugs}

Nicotine (free base, Sigma, catalog no. N3876) was dissolved in a 1:1 mixture of propylene glycol (Sigma, catalog no. W294004) and glycerol (Sigma, catalog no. G9012). Nicotine vapor was selfadministered via vapor chambers at specific concentrations $(0.05$, $0.5,0.74,5,6.67,20,40,50$, and $60 \mathrm{mg} / \mathrm{ml})$. Nicotine tartrate (Sigma, catalog no. SML1236) was dissolved in saline, and the $\mathrm{pH}$ was adjusted to 7.4 for intravenous nicotine delivery. Thirty minutes before the self-administration session, the a4 $\beta 2$ nicotinic acetylcholine receptor partial agonist and a7 receptor full agonist varenicline (Tocris, catalog no. 3754) was dissolved in saline and administered subcutaneously $(1.5 \mathrm{mg} / \mathrm{kg})$. To precipitate withdrawal, the nonspecific nicotinic acetylcholine receptor antagonist mecamylamine (Tocris, catalog no. 2843) was dissolved in saline and administered subcutaneously $(0.5$ and $1.5 \mathrm{mg} / \mathrm{kg})$ immediately after the self-administration session [22]. Behavioral testing occurred $30 \mathrm{~min}$ after mecamylamine administration.

\section{Vapor chambers}

The operant self-administration chambers were modified from standard housing cages (Fig. 1a) [23]. A press on the active lever was associated with the delivery of a puff of nicotine or vehicle vapor. A press on the inactive lever was not associated with any scheduled consequences. Every vapor puff was associated with 20-s illumination of a cue light above the active lever. During illumination of the cue light ( $20 \mathrm{~s}$ timeout period), active lever presses did not result in vapor release. Vapor was produced using a Nautilus electronic-vaporizer tank $(5 \mathrm{ml}, 3.3 \mathrm{~V}, 7.1 \mathrm{~W}$; Aspire, catalog no. SKU 305) using $1.6 \Omega$ coils. The tank was connected to a universal customized vaping machine (Gram Research). Input/ output chamber components were modulated by a Med Associates smart card (catalog no. DIG-716-B). The chambers contained one inch of bedding material. Figure 1a shows the chamber configuration. Each puff consisted of $90 \mathrm{ml}$ that was delivered over $3 \mathrm{~s}$, based on human studies that showed a similar volume/duration of puffs [24]. Electronic cigarette users tend to produce puffs that are longer and larger than traditional cigarette smokers [25]. With this configuration, an average of $8.7 \mu \mathrm{l}$ of nicotine-containing liquid was vaporized per puff. A vacuum line was used to clear the vapor from the chambers at a rate of $1 \mathrm{l} / \mathrm{min}$. The bedding material in the chambers was changed between sessions. All responses, including inactive lever presses and lever presses during the timeout period, were recorded by a computer.

\section{Experiment 1: Nicotine vapor dose response}

Rats ( $n=24$ [12 males, 12 females]) were given short access ( $1 \mathrm{~h}$ ) to nicotine vapor. The rats were initially trained to self-administer $0.5 \mathrm{mg} / \mathrm{ml}$ nicotine vapor in 14 consecutive daily sessions. The rats then had access to four doses of nicotine $(0.05,0.5,5$, and $50 \mathrm{mg} /$ $\mathrm{ml}$ ) in a 1:1 mixture of propylene glycol and glycerol using a within-subjects design. Each dose was tested in one session in the order of $50,5,0.05$, and $0.5 \mathrm{mg} / \mathrm{ml}$. The dose response was tested after Experiment 4. A separate counterpart cohort of rats $(n=24$ [11 males, 13 females]) was given short access $(1 \mathrm{~h})$ to vehicle (1:1, propylene glycol:glycerol) in 14 consecutive daily sessions. Blood samples were collected immediately after the self-administration session for each dose of nicotine (see Supplementary Material for more details).

Experiment 2: Validation of nicotine vapor self-administration The rats $(n=24$ [12 males, 12 females]) were allowed to selfadminister nicotine $(0.5 \mathrm{mg} / \mathrm{ml})$ or vehicle $(1: 1$, propylene glycol: glycerol; $n=24$, [11 males, 13 females]) vapor for $1 \mathrm{~h}$ daily for 14 sessions. The dose of nicotine $(0.5 \mathrm{mg} / \mathrm{ml})$ was based on preliminary pharmacokinetic data (not shown) because this dose produces blood nicotine levels that are relevant to human exposure $(20-80 \mathrm{ng} / \mathrm{ml})[26,27]$. See Supplementary Table S1 for blood level comparisons. The rats self-administered vapor for at least 14 days before behavioral testing because 1-2 weeks of passive nicotine exposure and intravenous self-administration have been shown to induce nicotine dependence in rodent models $[28,29]$.

Experiment 3: Effect of varenicline on vapor self-administration Rats ( $n=24$ [12 males, 12 females]) were allowed to selfadminister nicotine $(0.5 \mathrm{mg} / \mathrm{ml})$ or vehicle $(1: 1$, propylene glycol: glycerol; $n=24$ [11 males, 24 females]) vapor for $1 \mathrm{~h}$ daily for 14 sessions. After establishing a stable baseline level of selfadministration ( $\leq 20 \%$ variation), varenicline $(0.0$ or $1.5 \mathrm{mg} / \mathrm{kg}$ ) was administered subcutaneously $30 \mathrm{~min}$ before the selfadministration test. The rats were allowed to self-administer nicotine $(0.5 \mathrm{mg} / \mathrm{ml})$ or vehicle vapor in a 1-h session. The doses of varenicline were administered in a Latin square design.

Experiment 4: Mecamylamine-precipitated nicotine vapor withdrawal syndrome

Mechanical sensitivity. To test hyperalgesia, one of the main symptoms of nicotine withdrawal, paw withdrawal thresholds were measured in the von Frey test (see Supplementary Material for more details).

Somatic signs of withdrawal. Somatic signs of withdrawal were observed for a total of $30 \mathrm{~min}$ [28]. The rats were placed in a clear cylinder, and the following behaviors were recorded during the observation period: jumps, teeth chattering, ptosis, blinks, head shakes, paw tremors, abdominal contractions, genital licks, and yawns [28]. The sum of the observed behaviors served as an individual withdrawal score.

Experiment 5: Anxiety-like behavior during protracted abstinence from nicotine vapor

Anxiety-like behavior was measured in the elevated plus maze during protracted abstinence, 3 weeks after the last nicotine or vehicle vapor session [30]. Testing was performed under dim light (50 lux). Each rat was placed in the center of the maze facing an open arm at the start of the experiment. The time spent on the open and closed arms was recorded for $5 \mathrm{~min}$. An arm entry was defined as 3/4th of the rat's body within the arm.

Experiment 6: Reexposure to nicotine vapor-associated cues after protracted abstinence

After the last session of nicotine or vehicle vapor self-administration, the rats were left undisturbed in their home cages in the vivarium for 3 weeks with food and water available ad libitum. The rats were then returned to the self-administration chambers for $1 \mathrm{~h}$. The session was the same as described above in the "Vapor chambers" section, with the exception that active lever presses did not release nicotine or vehicle vapor. Instead, the cues (i.e., cue 
A

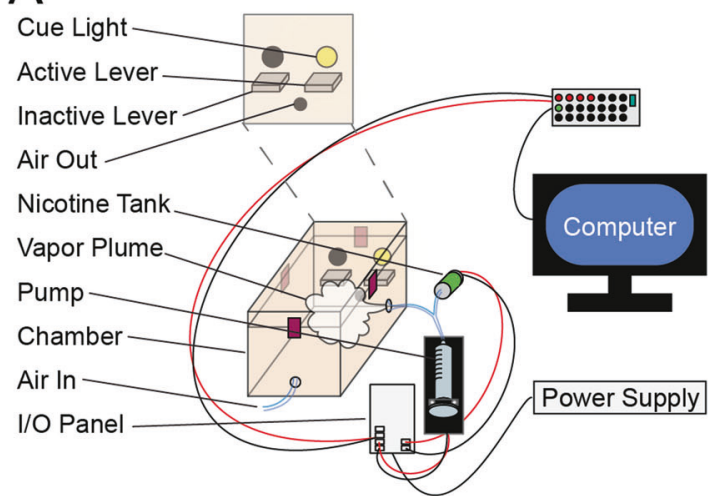

C
B

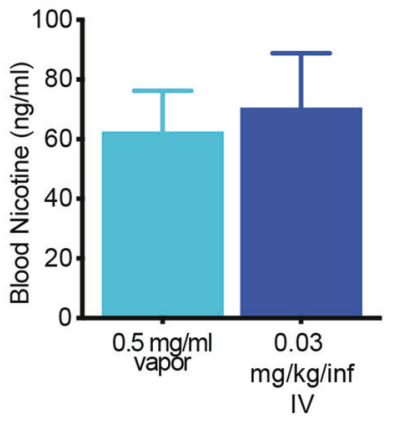

12 male, 12 female

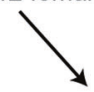

Organ Harvest Groups: Chronic Nicotine Nicotine Abstinent 6 male, 6 female

11 male, 13 female

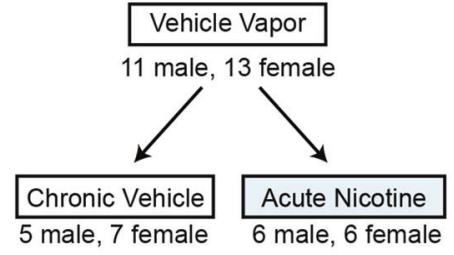

\begin{tabular}{|c|c|c|c|c|c|c|}
\multicolumn{1}{c}{14 days } & 3 days & \multicolumn{2}{c}{3 days } & days & \multicolumn{2}{c}{3 weeks } \\
\hline $\begin{array}{c}\text { Self-administration } \\
(0.5 \text { or } 0 \mathrm{mg} / \mathrm{ml})\end{array}$ & $\begin{array}{c}\text { Varenicline } \\
\text { Experiment }\end{array}$ & $\begin{array}{c}\text { Self-administration } \\
(0.5 \text { or } 0 \mathrm{mg} / \mathrm{ml})\end{array}$ & $\begin{array}{c}\text { Mecamylamine } \\
\text { Experiment }\end{array}$ & Abstinence & $\begin{array}{c}\text { Anxiety, Pain, } \\
\text { and Relapse }\end{array}$ & Organ Harvest \\
\hline
\end{tabular}

D
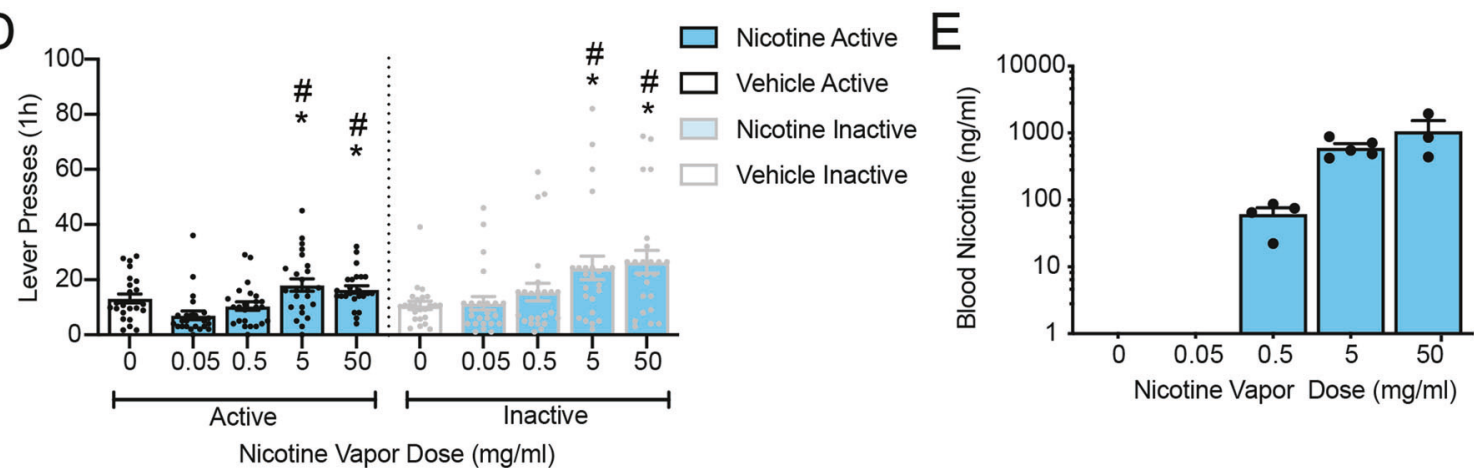

Fig. 1 Method development and experimental design. a Schematic diagram of the operant vapor self-administration chambers. b Comparison of blood nicotine levels between rats that self-administered nicotine vapor $(0.5 \mathrm{mg} / \mathrm{ml})$ and rats that self-administered nicotine intravenously $(0.03 \mathrm{mg} / \mathrm{kg} /$ infusion) in a 1 - $\mathrm{h}$ session. Error bars represent the SEM of blood nicotine concentration ( $n=3-4$ rats). c Experimental timeline of self-administration in the nicotine vapor group and vehicle vapor group. $\mathbf{d}$ Self-administration of vehicle vapor (0 $\mathrm{mg} / \mathrm{ml})$ and nicotine vapor $(0.05,0.5,5$, and $50 \mathrm{mg} / \mathrm{ml}, 1$ session/dose) in rats. The data are expressed as the mean \pm SEM of $16-24$ rats. e Blood nicotine levels in rats that self-administered vapor $(0,0.05,0.5,5$, and $50 \mathrm{mg} / \mathrm{ml}$ nicotine, $1 \mathrm{session} /$ dose). No nicotine was detected in blood from rats that self-administered vehicle vapor or vapor that contained $0.05 \mathrm{mg} / \mathrm{ml}$ nicotine. The data are expressed as the mean \pm SEM of 4-5 rats.

light and pump) that were associated with vapor administration were presented contingently upon active lever presses. The total number of responses on the active and inactive levers was recorded. The number of active lever presses during the session was compared with the number of active lever presses during nicotine vapor $(0.5 \mathrm{mg} / \mathrm{ml})$ self-administration.

Experiment 7: Heart weight and length analysis

The hearts were harvested from the four groups that are described in the "Histology and mean linear intercept analysis" section below. Using 200-mm calipers (Fisher), the length of each heart was measured from base to apex by two individual scorers [31]. The hearts were then weighed by two individual scorers using an electronic analytical balance (Mettler Toledo, catalog no. ML104/
03). The scores for each measurement were averaged per rat. Interrater reliability was $>0.85$.

Experiment 8: Histology and mean linear intercept analysis

The day after reexposure to nicotine vapor-associated cues after protracted abstinence, the rats were divided into four groups. Half of the nicotine vapor group underwent a nicotine vapor session (chronic nicotine group, $n=12$ [ 6 males, 6 females]), and the other half remained in protracted abstinence (nicotine abstinence group, $n=12$ [ 6 males, 6 females]). Half of the vehicle vapor group underwent a nicotine vapor session (acute nicotine group, $n=12$ [ 6 males, 6 females]), and the other half remained in protracted abstinence (chronic vehicle group, $n=12$ [6 males, 6 females]). The lungs were inflated with $4 \%$ paraformaldehyde 
(VWR, catalog no. 100496-496) and fixed overnight at $4{ }^{\circ} \mathrm{C}$ (see Supplementary Material for more details).

Experiment 9: Receptor dysregulation during protracted abstinence

Rats were sacrificed by $\mathrm{CO}_{2}$ inhalation, and brains were removed and snap frozen in 2-methylbutane. Tissue micropunches were taken from 300- $\mu \mathrm{m}$-thick slices of the nucleus accumbens and medial prefrontal cortex. The tissue was immediately frozen on dry ice, and samples were kept at $-80^{\circ} \mathrm{C}$ until use (see Supplementary Material for more details).

Statistical analysis

The data were analyzed using Prism 8.0 software (GraphPad). All of the active and inactive lever presses that are reported in the selfadministration and varenicline experiments do not include lever presses during the 20-s timeout period. The active and inactive lever presses that are reported in the reexposure experiment include lever presses during the 20-s timeout period. The dose response results were initially analyzed using mixed-effects (twoway) analysis of variance (ANOVA), with training condition (nicotine vapor or vehicle vapor) and lever (active lever or inactive lever) as factors. Significant interactions were followed by one-way between-subjects ANOVA of the appropriate independent variables. The self-administration results were initially analyzed using mixed-effects (three-way) ANOVA, with training condition (nicotine vapor or vehicle vapor) and lever (active lever or inactive lever) as factors. Significant interactions in the mixed-effects ANOVA were followed by two-way ANOVA of the appropriate variables. The behavioral results were analyzed using one-way ANOVA or Students $t$ test where appropriate. Significant effects in the one- and two-way ANOVAs were followed by the Newman-Keuls post hoc test. Values of $p<0.05$ were considered statistically significant. The heart weight and length data were analyzed between groups and sexes using two-way ANOVA. The heart data were then analyzed by controlling for body weight on the day of sacrifice using analysis of covariance (ANCOVA) and R software, with body weight as the covariate, heart measurement as the dependent variable, and group as the factor variable. The mRNA data were analyzed using the $\Delta \Delta C_{t}$ method and are expressed as fold changes $\left(2^{-\Delta \Delta C t}\right)$. Unpaired $t$-tests were used to compare means between groups. Grubb's outlier test was performed to justify the removal of outliers. The statistical analyses were performed using Prism 8 software.

\section{RESULTS}

Experiment 1: Nicotine vapor dose response

The two-way repeated-measures mixed-effects ANOVA of the vehicle and nicotine groups combined showed significant effects of dose $\left(F_{4,115}=7.085, p<0.0001\right)$ and lever $\left(F_{1,115}=11.18, p<\right.$ $0.001)$ but no significant dose $\times$ lever interaction $\left(F_{4,115}=2.122\right.$, $p>0.05)$. The between-subjects one-way ANOVA of active lever presses showed a significant main effect of dose $\left(F_{4,111}=8.907\right.$, $p<0.0001)$. The Newman-Keuls multiple-comparison post hoc test indicated significant differences between vehicle and the 5 and $50 \mathrm{mg} / \mathrm{ml}$ doses of nicotine ( $p<0.01$ and $p<0.05$, respectively). The between-subjects one-way ANOVA of inactive lever presses showed a significant main effect of dose $\left(F_{4,111}=2.834, p<0.05\right)$. The Newman-Keuls multiple-comparison post hoc test indicated significant differences between vehicle and the 5 and $50 \mathrm{mg} / \mathrm{ml}$ doses of nicotine $(p<0.05$ and $p<0.01$, respectively) and significant differences between the $0.05 \mathrm{mg} / \mathrm{ml}$ dose and 5 and $50 \mathrm{mg} / \mathrm{ml}$ doses $(p<0.05$ and $p<0.01$, respectively). Blood nicotine levels were analyzed immediately following the session (Fig. 1e, Supplementary Fig. S2). To compare these blood nicotine levels to literature reports of blood nicotine levels after bolus intravenous injections in rats (Supplementary Table S2), we determined the linear relationship between intravenous dose and plasma nicotine levels (Supplementary Fig. S3). The projected equivalent bolus intravenous injection dose was then calculated for each nicotine vapor dose that was tested in the dose-response curve (Supplementary Table S3). The highest rate of responding was observed for $5 \mathrm{mg} / \mathrm{ml}$ nicotine.

Experiment 2: Validation of nicotine vapor self-administration To further validate the vapor self-administration model, we selected a dose of nicotine $(0.5 \mathrm{mg} / \mathrm{ml})$ that produced blood nicotine levels in the $20-80 \mathrm{ng} / \mathrm{ml}$ range, similar to human smokers and vapers $[24,26,32]$. At the $0.5 \mathrm{mg} / \mathrm{ml}$ dose of nicotine, the rats lever pressed for an average of $\sim 9 \mathrm{puffs} / \mathrm{h}$, resulting in blood nicotine levels of $\sim 62 \mathrm{ng} / \mathrm{ml}$ (Fig. 1b). The current gold-standard animal model of nicotine use is intravenous self-administration [33, 34]. Therefore, we confirmed that our nicotine vapor model produced similar blood nicotine levels as the intravenous model (Fig. 1b). The remaining experiments were conducted at the $0.5 \mathrm{mg} / \mathrm{ml}$ dose (Fig. 1c). During the last 3 days of self-administration, rats in the nicotine vapor group exhibited $8.3 \%$ variation in intake, whereas the vehicle vapor selfadministration group exhibited $14.3 \%$ variation in intake (Fig. 2 b).

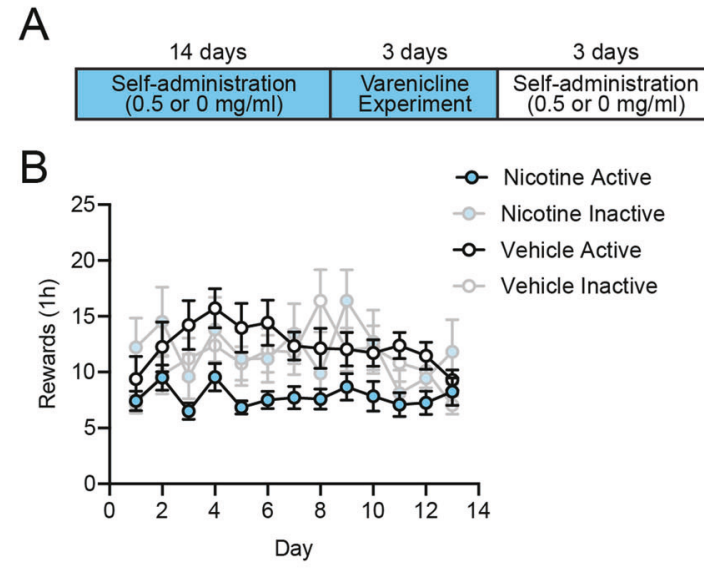

\begin{tabular}{c|c|c|c|}
\multicolumn{1}{c}{3 days } & 3 weeks & \multicolumn{1}{c}{1 day } & 1 day \\
$\begin{array}{c}\text { Mecamylamine } \\
\text { Experiment }\end{array}$ & Abstinence & $\begin{array}{c}\text { Anxiety, Pain, } \\
\text { and Relapse }\end{array}$ & Organ Harvest \\
\hline
\end{tabular}

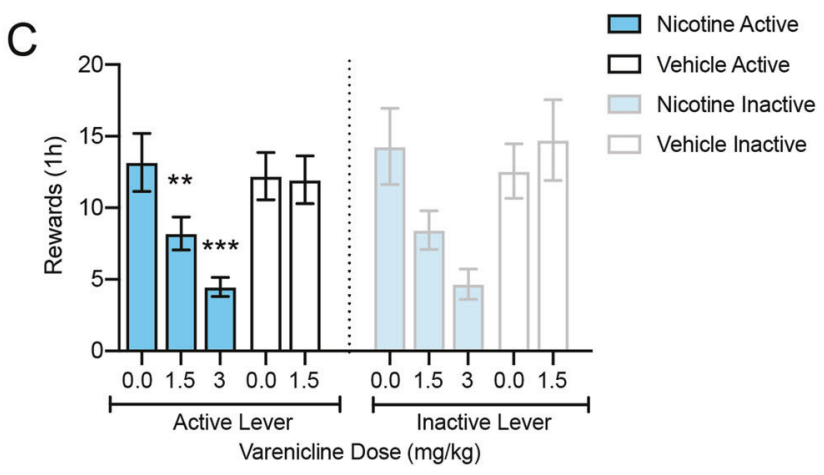

Fig. 2 Varenicline decreased nicotine vapor self-administration. a Experimental timeline of self-administration in the nicotine vapor group and vehicle vapor group. b Acquisition and maintenance of nicotine vapor self-administration during 2 weeks of daily short access (1 h) to nicotine vapor $(0.5 \mathrm{mg} / \mathrm{ml}, n=24$ [12 females, 12 males]) or vehicle vapor (1:1, propylene glycol:glycerol, $n=24$ [13 females, $11 \mathrm{males}$ ]). Error bars represent the SEM of lever presses. c Nicotine vapor and vehicle vapor self-administration following pretreatment with varenicline (1.5 $\mathrm{mg} / \mathrm{ml}$, s.c.). Error bars represent the SEM of lever presses. 


\begin{tabular}{c|c|c|c|c|c|c|}
\hline 14 days & \multicolumn{2}{c}{3 days } & \multicolumn{2}{c}{3 days } & days & \multicolumn{2}{c}{3 weeks } & day & day \\
\hline $\begin{array}{c}\text { Self-administration } \\
(0.5 \text { or } 0 \mathrm{mg} / \mathrm{ml})\end{array}$ & $\begin{array}{c}\text { Varenicline } \\
\text { Experiment }\end{array}$ & $\begin{array}{c}\text { Self-administration } \\
(0.5 \mathrm{or} 0 \mathrm{mg} / \mathrm{ml})\end{array}$ & $\begin{array}{c}\text { Mecamylamine } \\
\text { Experiment }\end{array}$ & Abstinence & $\begin{array}{c}\text { Anxiety, Pain, } \\
\text { and Relapse }\end{array}$ & Organ Harvest \\
\hline
\end{tabular}
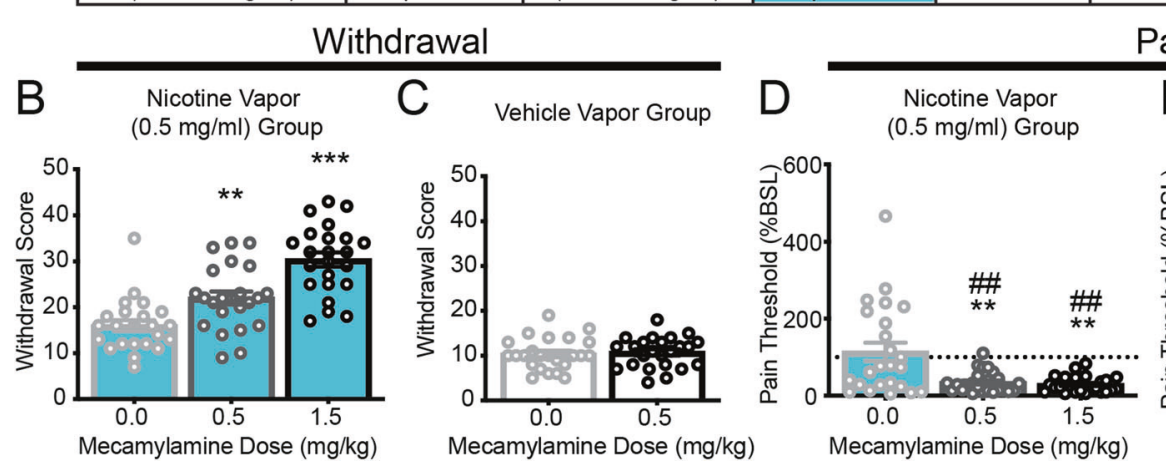

Pain

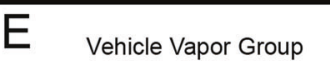

Fig. 3 Rats that self-administered nicotine vapor exhibited dependence-like behaviors during mecamylamine-precipitated withdrawal. a Experimental timeline of the behavioral analysis in the nicotine vapor group and vehicle vapor group. $\mathbf{b}$ Withdrawal scores in rats that selfadministered nicotine vapor $(0.5 \mathrm{mg} / \mathrm{ml})$ increased following subcutaneous mecamylamine administration $(0.5$ or $1.5 \mathrm{mg} / \mathrm{ml})$. Error bars represent the SEM of withdrawal score $(n=24$ rats [12 females, 12 males]). c Withdrawal scores in rats that self-administered vehicle vapor $(1: 1$, propylene glycol:glycerol) following subcutaneous mecamylamine administration did not change $(0.5 \mathrm{mg} / \mathrm{ml})$. Error bars represent the SEM of withdrawal scores ( $n=24$ rats [13 females, 11 males]). d The percent change in pain thresholds relative to baseline (BSL) in rats that selfadministered nicotine vapor $(0.5 \mathrm{mg} / \mathrm{ml})$ decreased following subcutaneous mecamylamine administration $(0.5 \mathrm{mg} / \mathrm{ml})$. Error bars represent the SEM of the percent change in pain thresholds relative to baseline ( $n=24$ rats [12 males, 12 females]). e Mecamylamine had no effect on pain thresholds in rats that self-administered vehicle vapor $(0.5 \mathrm{mg} / \mathrm{ml})$. Error bars represent the SEM of the percent change in pain thresholds relative to baseline ( $n=24$ rats [13 males, 11 females]).

The mixed-factorial ANOVA of the nicotine and vehicle groups combined indicated a significant effects of training condition $\left(F_{1,597}=11.36, p<0.001\right)$, of levers $\left(F_{1,597}=9.688, p<0.01\right)$ and a significant training condition $\times$ lever interaction $\left(F_{12,597}=45.68\right.$, $p<0.0001)$. Lever discrimination was further examined in both the nicotine and vehicle groups (Supplementary Fig. S3). Discrimination was defined as the acquisition of $>50 \%$ nicotine-containing puffs derived from active lever presses relative to the total number of lever presses while excluding lever presses during the 20-s timeout derived from the active and inactive lever presses combined. Based on this criterion for discrimination, 14 rats in the nicotine group were classified as discriminators, and 10 rats were classified as nondiscriminators. In the vehicle group, 17 rats were classified as discriminators, and seven rats were classified as nondiscriminators. In the discriminator group (Supplementary Fig. S3A), the mixed-factorial ANOVA of the nicotine and vehicle groups combined indicated significant effects of lever $\left(F_{1,376}=\right.$ 86.27, $p<0.001)$ and training condition $\left(F_{1,377}=60.79, p<0.0001\right)$ and a significant training condition $\times$ lever interaction $\left(F_{1,376}=\right.$ $21.87, p<0.0001$ ). In the nondiscriminator group (Supplementary Fig. S3B), the mixed-factorial ANOVA of the nicotine and vehicle groups combined indicated a significant effect of lever $\left(F_{1,195}=\right.$ $190.4, p<0.001)$, no effect of training condition $\left(F_{1,195}=0.008349\right.$, $p>0.05)$, and no effect of session $\left(F_{1,195}=0.6070, p>0.05\right)$.

Experiment 3: Effect of varenicline on vapor self-administration The two-way ANOVA of the effect of varenicline on active lever presses showed a significant effect of varenicline dose $\left(F_{2,46}=\right.$ 5.747, $p<0.05)$ and a significant varenicline dose $\times$ training condition interaction $\left(F_{2,46}=4.697, p<0.05\right)$. The Newman-Keuls multiple-comparison post hoc test revealed a significant decrease in nicotine vapor self-administration in rats that were treated with $1.5 \mathrm{mg} / \mathrm{kg}$ varenicline compared with $0 \mathrm{mg} / \mathrm{kg}$ varenicline-treated rats $(p<0.01)$. The Newman-Keuls multiple-comparison post hoc test also revealed no effect of varenicline on active lever presses in the vehicle vapor group $(p>0.9999)$. The two-way ANOVA of the effect of varenicline on inactive lever presses showed no effect of varenicline dose $\left(F_{2,46}=2.648, p>0.05\right)$ and no effect of training condition $\left(F_{2,46}=0.5801, p>0.05\right)$. The Newman-Keuls multiplecomparison post hoc test revealed a significant decrease in inactive lever presses in nicotine vapor self-administration rats that were treated with $1.5 \mathrm{mg} / \mathrm{kg}$ varenicline compared with $0 \mathrm{mg} /$ $\mathrm{kg}$ varenicline-treated rats $(p<0.01)$. The Newman-Keuls multiplecomparison post hoc test also revealed no effect of varenicline on inactive lever presses in the vehicle vapor group $(p>0.05)$.

Experiment 4: Mecamylamine-precipitated nicotine vapor withdrawal syndrome

The nicotine vapor group exhibited significantly higher somatic signs of withdrawal with both doses of mecamylamine compared with baseline (one-way ANOVA, $F_{2,40}=25.47, p<0.0001$; Fig. $3 b$ ). The Newman-Keuls multiple-comparison post hoc test revealed a significant increase in somatic signs of withdrawal in mecamylamine-treated rats compared with vehicle-treated rats $(p<0.01,0.5 \mathrm{mg} / \mathrm{kg}$ vs. $0.0 \mathrm{mg} / \mathrm{kg}$ and $p<0.001,1.5 \mathrm{mg} / \mathrm{kg}$ vs. 0.0 $\mathrm{mg} / \mathrm{kg}$ ). In the vehicle vapor group, the lowest effective dose of mecamylamine had no effect on somatic signs of withdrawal (Student's $t$ test, $t_{46}=0.3729, p=0.7109$; Fig. 3c).

In the nicotine vapor group, hyperalgesia/allodynia was observed with each dose of mecamylamine (one-way ANOVA, $F_{1,24}=13.88$, $p=0.001$; Fig. $3 \mathrm{~d}$ ). The Newman-Keuls multiple-comparison post hoc test revealed a significant decrease in pain thresholds in mecamylamine-treated rats compared with vehicle-treated rats $(p<$ $0.01,0.5$ and $1.5 \mathrm{mg} / \mathrm{kg}$ mecamylamine vs. $0.0 \mathrm{mg} / \mathrm{kg}$ ). Pain thresholds in rats that underwent withdrawal were lower compared with their own baseline thresholds before nicotine vapor selfadministration after $0.5 \mathrm{mg} / \mathrm{kg}$ mecamylamine (one-sample $t$-test, $t_{23}=11.62, p<0.0001$ ) and $1.5 \mathrm{mg} / \mathrm{ml}$ mecamylamine (one-sample $t$-test, $t_{23}=16.12, p<0.0001$; Fig. 3d). Mecamylamine-precipitated withdrawal $(0.5 \mathrm{mg} / \mathrm{kg})$ had no effect in the vehicle vapor group (Student's $t$ test, $t_{23}=0.8398, p=0.4097$; Fig. 3e). These results indicated that daily nicotine vapor self-administration produced nicotine dependence after only 12 days. However, unknown is whether a history of nicotine vaping may also affect addiction-like behaviors after protracted abstinence. This is an important issue because relapse in humans usually occurs weeks after initial withdrawal symptoms due to a combination of increases in craving and negative emotional states [13]. Indeed, hyperalgesia/allodynia was still evident in the nicotine vapor group during protracted abstinence compared with their own baseline (one-sample $t$-test, 


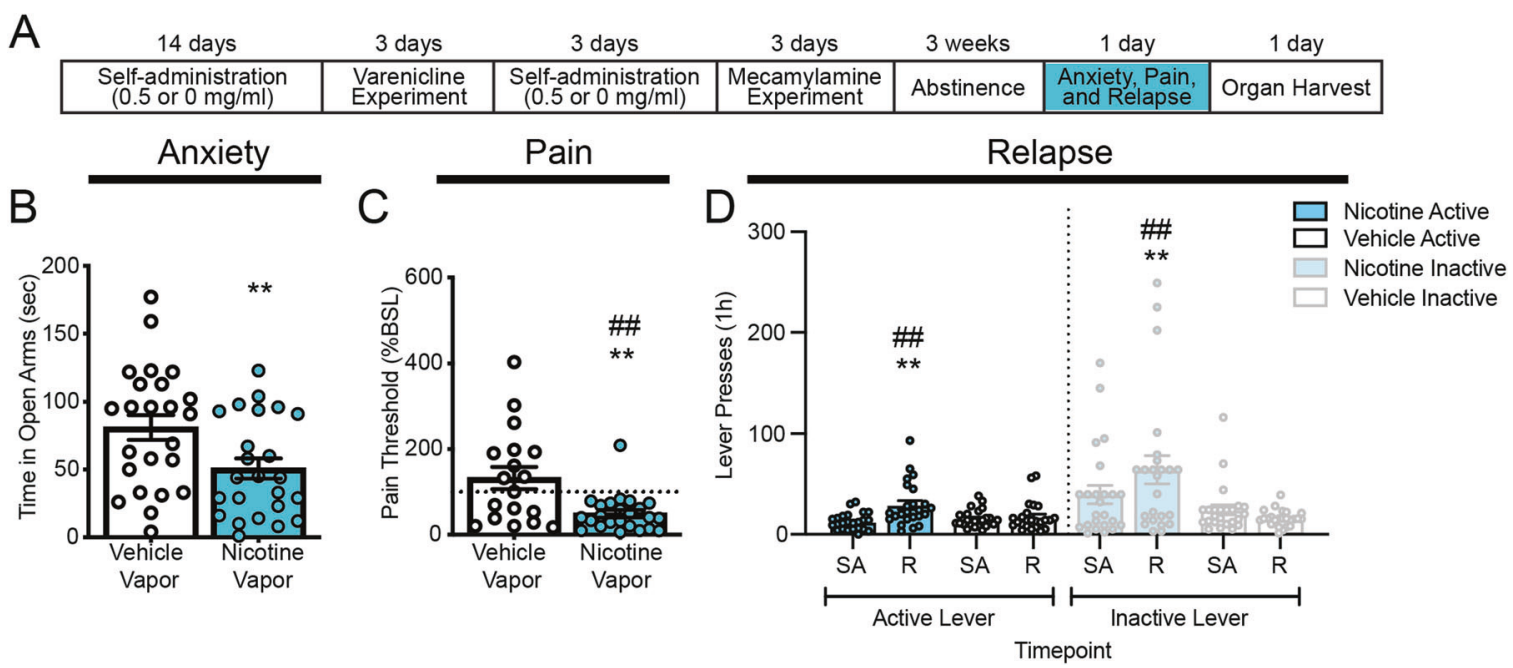

Fig. 4 Rats that self-administered nicotine vapor exhibited addiction-like behaviors after 3 weeks of protracted abstinence. a Experimental timeline of the behavioral analysis in the nicotine vapor group and vehicle vapor group. $\mathbf{b}$ The time spent in the open arms of the elevated plus maze decreased in rats that self-administered nicotine vapor compared with vehicle vapor. Error bars represent the SEM of the time spent on the open arms ( $n=24$ rats [12-13 females, 11-12 males]). c The percent change in pain thresholds relative to baseline in rats that self-administered nicotine vapor decreased compared with their own baseline (BSL) and with vehicle vapor during protracted abstinence following a 3-week incubation period. Error bars represent the SEM of the percent change in pain thresholds relative to baseline $(n=24$ rats [12-13 females, 11-12 males]). d Number of lever presses in the nicotine vapor group ( $n=24$ rats [12 females, 12 males]) and vehicle vapor group ( $n=24$ rats [13 females, 11 males]) in a 1-h session before (self-administration [SA]) and after (reexposure [R]) a 3 -week incubation period. Error bars represent the SEM of the number of lever presses.

$\left.t_{23}=5.891, p<0.0001\right)$ and the vehicle vapor group (Student's $t$ test, $t_{23}=5.084, p<0.0001$; Fig. 4c).

Experiment 5: Anxiety-like behavior during protracted abstinence from nicotine vapor

To test whether daily nicotine vapor self-administration $(1 \mathrm{~h} /$ day, $0.5 \mathrm{mg} / \mathrm{ml}$ ) produces negative emotional states after protracted abstinence, we measured anxiety-like behavior after 3 weeks of abstinence [13, 35] (Fig. 4a). The elevated plus maze was used to measure anxiety-like behavior in both groups of rats during protracted abstinence. The time spent on the open arms significantly decreased in the nicotine vapor group compared with the vehicle vapor group (Student's $t$ test, $t_{46}=2.724, p=$ 0.0091; Fig. 4b).

Experiment 6: Reexposure to nicotine vapor-associated cues after protracted abstinence

The mixed-effect ANOVA of the vehicle and nicotine groups combined showed a significant effect of training condition $\left(F_{1,92}\right.$ $=18.69, p<0.0001)$ and a significant effect of levers $\left(F_{1,92}=12.35\right.$, $p<0.001)$. Data showed a significant interaction for reexposure $\times$ lever $\left(F_{1,92}=5.405, p<0.05\right)$ and training condition $\times$ lever interaction $\left(F_{1,92}=11.65, p<0.001\right)$. The two-way ANOVA analysis of the active lever presses showed a significant effect of cue reexposure $\left(F_{1,46}=11.57, p<0.01\right)$ and a significant training condition $\times$ cue reexposure interaction $\left(F_{1,46}=7.411, p<0.01\right)$. The Newman-Keuls multiple-comparison post hoc test revealed a significant increase in active lever presses in the nicotine vapor group from the self-administration to reexposure timepoint $(p<$ 0.001 ) and a significant difference between the nicotine group and vehicle group at the reexposure timepoint $(p<0.05)$. No statistically significant change in the active lever from the selfadministration to the reexposure timepoint of the vehicle group was observed $(p>0.05)$. The two-way ANOVA of inactive lever presses showed a significant effect of training condition $\left(F_{1,46}=\right.$ $9.412, p<0.01)$ and no effect of cue reexposure $\left(F_{1,46}=1.375, p>\right.$ $0.05)$. The Newman-Keuls multiple-comparison post hoc test revealed a significant increase in inactive lever presses in the nicotine vapor group from the self-administration to the reexposure timepoint $(p<0.05)$ and a significant difference between the nicotine group and vehicle group at the reexposure timepoint $(p<0.001)$. The Newman-Keuls multiple-comparison post hoc test revealed no significant change in the inactive lever from the self-administration to the reexposure timepoint of the vehicle group $(p>0.05)$.

Experiment 7: Heart weight and length analysis

Across all groups, males had longer hearts than females $\left(F_{1,40}=\right.$ 175.6, $p<0.0001$; Supplementary Fig. S4A). Rats that selfadministered nicotine chronically exhibited a shorter heart length after controlling for body weight $\left(F_{4,43}=86.73, p<0.0001\right)$. Similar to heart length, males had heavier hearts than females (two-way ANOVA, $F_{1,40}=177.5, p<0.0001$; Supplementary Fig. S4B). Rats that self-administered nicotine chronically exhibited lower heart weights after controlling for body weight $\left(F_{4,43}=53.6, p<0.0001\right)$, similar to observations after high doses $(6-12 \mathrm{mg} / \mathrm{kg} /$ day $)$ of nicotine that was administered subcutaneously for 14 days [31].

Experiment 8: Histology and mean linear intercept analysis The alveolar airspace was simplified in the lungs in rats that were exposed to chronic nicotine compared with rats that administered vehicle vapor and rats that received only acute exposure to nicotine (Fig. 5b-e). Rats that were subjected to 3 weeks of protracted abstinence following chronic nicotine administration did not exhibit improvements in alveolar airspace $\left(F_{3,92}=11.69\right.$, $p<0.0001$; Fig. 5f). The Newman-Keuls multiple-comparison post hoc test revealed a significant increase in the mean linear intercept in the nicotine groups compared with the chronic vehicle $(p<0.001)$ and acute nicotine $(p<0.01)$ groups.

Experiment 9: Receptor dysregulation during protracted abstinence

During protracted abstinence, significant decreases in a4 and $\beta 2$ nicotinic acetylcholine receptor subunit gene expression were observed in the nucleus accumbens in rats that self-administered nicotine vapor compared with rats that self-administered vehicle vapor (a4: unpaired $t$-test, $t_{13}=3.386, p<0.01$, Fig. $6 \mathrm{~b}$; $\beta 2$ : unpaired $t$-test, $t_{13}=3.142, p<0.01$, Fig. $6 c$ ), with no change in a3 nicotinic 
A

\begin{tabular}{|c|c|c|c|c|c|c|} 
A 14 days & 3 days & \multicolumn{2}{c}{3 days } & days & \multicolumn{2}{c}{3 weeks } \\
\hline $\begin{array}{c}\text { Self-administration } \\
(0.5 \text { or } 0 \mathrm{mg} / \mathrm{ml})\end{array}$ & $\begin{array}{c}\text { Varenicline } \\
\text { Experiment }\end{array}$ & $\begin{array}{c}\text { Self-administration } \\
(0.5 \text { or } 0 \mathrm{mg} / \mathrm{ml})\end{array}$ & $\begin{array}{c}\text { Mecamylamine } \\
\text { Experiment }\end{array}$ & Abstinence & $\begin{array}{c}\text { Anxiety, Pain, } \\
\text { and Relapse }\end{array}$ & Organ Harvest \\
\hline
\end{tabular}
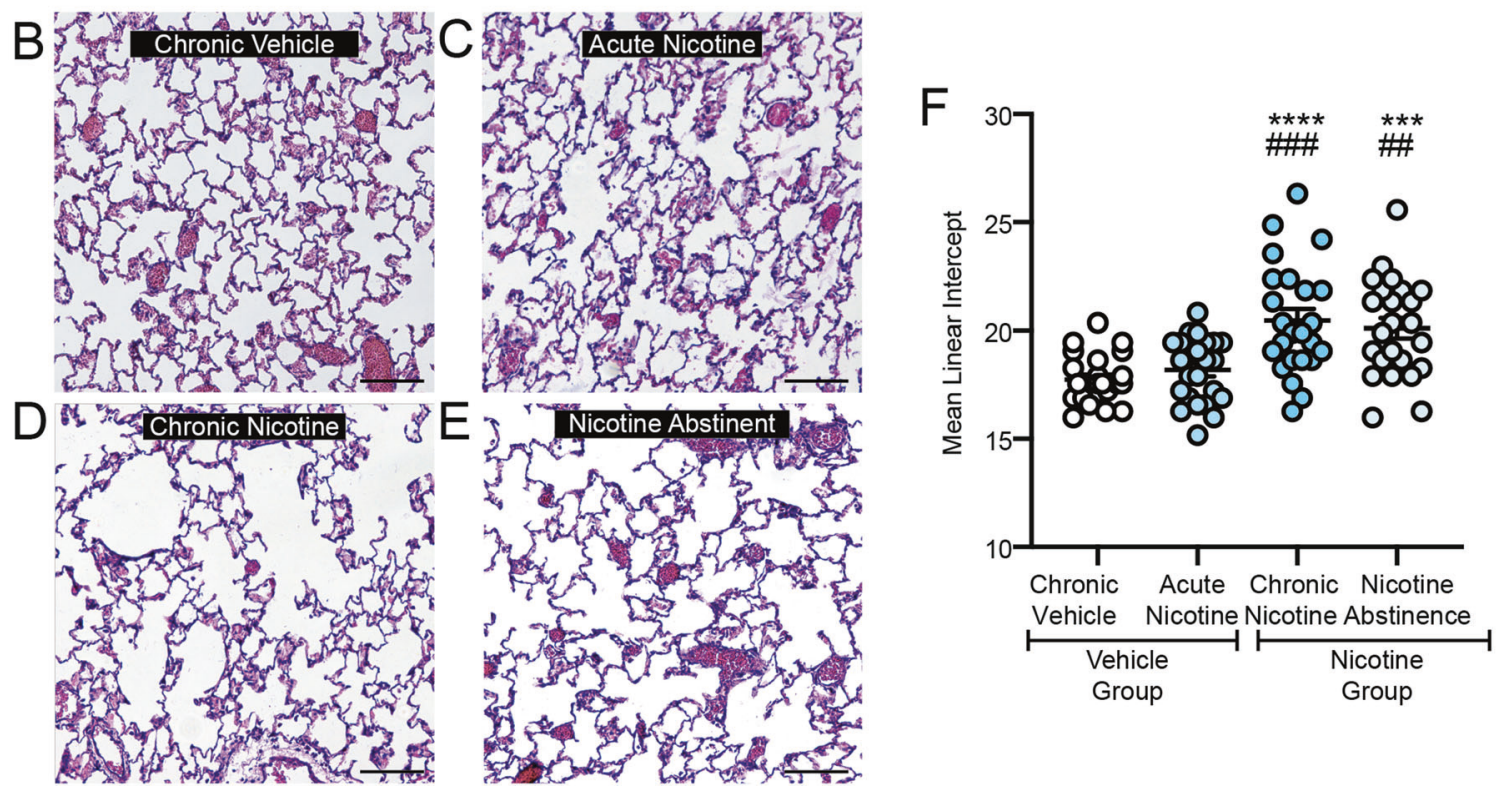

Fig. 5 Three weeks of daily $(1 \mathrm{~h})$ nicotine vapor self-administration produced alveolar simplification. a Experimental timeline of organ harvest in the nicotine vapor group and vehicle vapor group. Representative images of hematoxylin and eosin staining of the lungs in rats that self-administered (b) chronic vehicle vapor, c acute nicotine vapor $(0.5 \mathrm{mg} / \mathrm{ml}$, one session), d chronic nicotine vapor $(0.5 \mathrm{mg} / \mathrm{ml}$, 23 sessions), and e chronic nicotine vapor $(0.5 \mathrm{mg} / \mathrm{ml}, 23$ sessions) after 3 weeks of abstinence. $\mathbf{f}$ The mean linear intercept of alveolar airspace distance increased in rats that chronically self-administered nicotine vapor compared with vehicle vapor and acute self-administration. Error bars represent the SEM of six tissue sample replicates per rat $(n=4$ rats [ 2 females, 2 males]).

acetylcholine receptor subunit gene expression in the nucleus accumbens between groups (unpaired $t$-test, $t_{14}=0.7339, p>0.05$; Fig. $6 \mathrm{~d}$ ). A significant increase in a3 nicotinic acetylcholine receptor subunit gene expression was observed in the medial prefrontal cortex in rats that self-administered nicotine vapor compared with rats that self-administered vehicle (unpaired $t$-test, $t_{14}=2.294, p<$ 0.05 ; Fig. $6 \mathrm{~g}$ ), with no changes in a4 (unpaired $t$-test, $t_{14}=0.9960, p$ $>0.05$; Fig. 6e) or $\beta 2$ (unpaired $t$-test, $t_{14}=0.01653, p>0.05$; Fig. $6 f$ ) nicotinic acetylcholine receptor subunit gene expression.

\section{DISCUSSION}

The present study validated a nicotine vapor self-administration method in rats with clinically relevant pharmacology (Fig. 1), the characterization of a dose-response (Fig. 1d), and the maintenance of drug taking (Fig. 2). The level of responding on the active (nicotine) lever was similar to the inactive (air) lever and lower than the active lever that was associated with vehicle (polypropylene glycol/glycerol) vapor, suggesting low positive reinforcing effects and low nicotine vapor discrimination. Varenicline attenuated nicotine vapor self-administration in the active and inactive lever, suggesting that nicotinic acetylcholine receptors mediated lever pressing behavior (Fig. 2). Moreover, chronic nicotine vapor self-administration produced symptoms of dependence, including mecamylamine-precipitated hyperalgesia/ allodynia and somatic signs of withdrawal (Fig. 3). Hyperalgesia/ allodynia persisted in protracted abstinence without pharmacological precipitation and was accompanied by anxiety-like behavior (Fig. 4). Three weeks of daily $(1 \mathrm{~h})$ nicotine vapor selfadministration produced relapse-like behavior, measured as increases in active and inactive lever pressing following reexposure to vapor-associated cues after protracted abstinence (Fig. 4). Nicotine vapor self-administration ( 3 weeks, $1 \mathrm{~h} /$ day) decreased heart length and weight (Supplementary Fig. S4) and induced alveolar simplification (Fig. 5). Finally, long-term changes in nicotinic acetylcholine receptor subunit gene expression were observed during protracted abstinence (Fig. 6).

\section{Nicotine vapor dose}

In Experiment 1, rats self-administered a wide range of nicotine solutions $(0.05-50 \mathrm{mg} / \mathrm{ml})$ according to an inverted-U dose-response curve, which is typically seen with nicotine $[36,37]$ and other psychostimulants [38]. Self-administration of the $0.5 \mathrm{mg} / \mathrm{ml}$ nicotine dose led to blood nicotine levels that were very similar to human smokers and rats that self-administer nicotine intravenously at the optimal dose of nicotine $(0.03 \mathrm{mg} /$ $\mathrm{kg} / \mathrm{inj}$ ) [39]. Interestingly, rats also self-administered much higher doses of nicotine vapor that led to blood nicotine levels that were higher than human smokers but similar to blood nicotine levels in rats during conditioned place preference [40]. This is interesting because one critique of the conditioned place preference paradigm has been that the high dose of nicotine that is required to observe an effect is unattainable through self-administration in rats. However, the present results may resolve this issue by demonstrating that such high blood nicotine levels can be achieved through the pulmonary route and suggest that rats develop high tolerance to nicotine through this route of administration. The goal of the present study was to validate a model that is relevant to electronic cigarette use in humans. Therefore, our subsequent experiments were conducted using the $0.5 \mathrm{mg} / \mathrm{ml}$ dose that produced blood nicotine levels that were similar to human chronic smokers (Supplementary Table S1). In contrast to the inverted- $U$ shape of responding on the active lever, a dose-dependent increase in responding on the inactive lever was observed, which mirrored blood nicotine levels and suggests that the increase in inactive lever pressing may have been 
A

\begin{tabular}{|c|c|c|c|c|c|c|}
\hline & 3 days & 3 days & 3 days & days & 3 weeks & day \\
\hline $\begin{array}{c}\text { Self-administration } \\
(0.5 \text { or } 0 \mathrm{mg} / \mathrm{ml})\end{array}$ & $\begin{array}{c}\text { Varenicline } \\
\text { Experiment }\end{array}$ & $\begin{array}{c}\text { Self-administration } \\
(0.5 \text { or } 0 \mathrm{mg} / \mathrm{ml})\end{array}$ & $\begin{array}{c}\text { Mecamylamine } \\
\text { Experiment }\end{array}$ & Abstinence & $\begin{array}{c}\text { Anxiety, Pain, } \\
\text { and Relapse }\end{array}$ & Organ Harvest \\
\hline
\end{tabular}

B

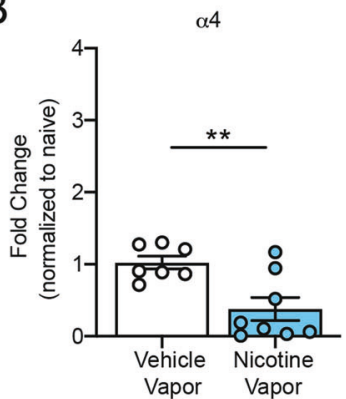

C

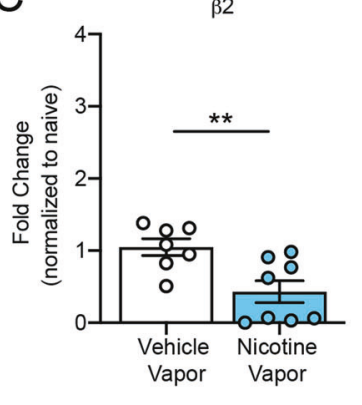

D

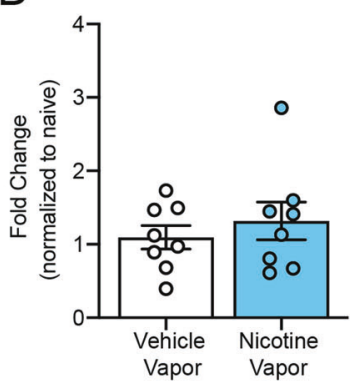

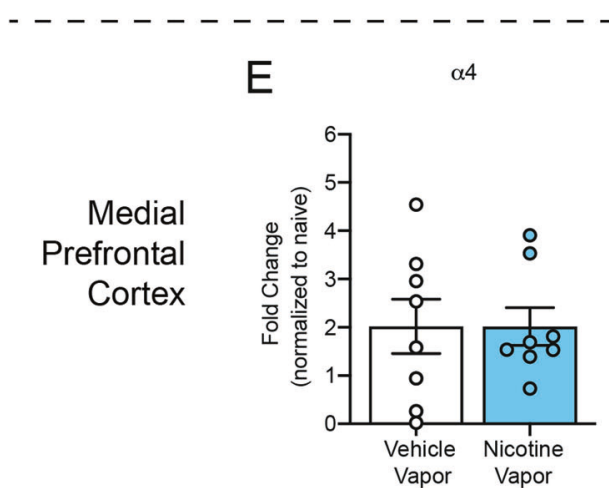

F

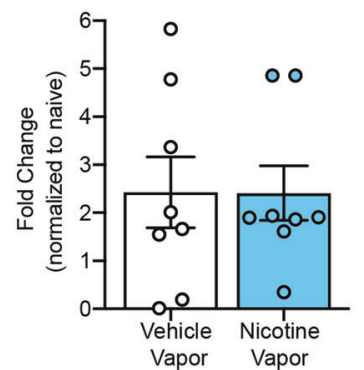

G

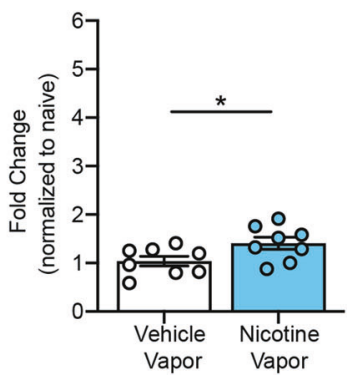

Fig. 6 Receptor dysregulation after protracted abstinence from nicotine vaping. a Experimental timeline of brain harvest in the nicotine vapor group and vehicle vapor group. $\mathbf{b}$ Change in $\alpha 4$ nicotinic acetylcholine receptor subunit gene expression in the nucleus accumbens in rats that self-administered vehicle vapor and nicotine vapor after 3 weeks of protracted abstinence. c Change in $\beta 2$ nicotinic acetylcholine receptor subunit gene expression in the nucleus accumbens in rats that self-administered vehicle vapor and nicotine vapor after 3 weeks of protracted abstinence. d Change in $\alpha 3$ nicotinic acetylcholine receptor subunit gene expression in the nucleus accumbens in rats that selfadministered vehicle vapor and nicotine vapor after 3 weeks of protracted abstinence. e Change in $\alpha 4$ nicotinic acetylcholine receptor subunit gene expression in the medial prefrontal cortex in rats that self-administered vehicle vapor and nicotine vapor after 3 weeks of protracted abstinence. $\mathbf{f}$ Change in $\beta 2$ nicotinic acetylcholine receptor subunit gene expression in the medial prefrontal cortex in rats that selfadministered vehicle vapor and nicotine vapor after 3 weeks of protracted abstinence. $\mathbf{g}$ Change in $\alpha 3$ nicotinic acetylcholine receptor subunit gene expression in the medial prefrontal cortex in rats that self-administered vehicle vapor and nicotine vapor after 3 weeks of protracted abstinence. Error bars represent the mean \pm SEM of the fold change in gene expression, normalized to the vapor group ( $n=7-8$ rats).

attributable to nicotine-induced hyperactivity. In addition, there is likely a difference in the discriminative stimulus effects of nicotine vapor self-administration compared with intravenous nicotine selfadministration. In models of intravenous self-administration, the reinforcer is injected directly into the bloodstream over 3-20 s after a press on the active lever. However, in the present model of vapor self-administration, the vapor entered the rats' environment (i.e., the chamber) over $\sim 20 \mathrm{~s}$ after an active lever press (Fig. S1). Furthermore, the rats self-administered the vapor to keep the chamber saturated with vapor throughout the 1-h session, a phenomenon that is not possible with intravenous selfadministration. The ambiguous nature of the "reward" delivery likely causes difficulty in lever discrimination. Future studies should increase the fixed-ratio schedule, lengthen the timeout period, retract the levers after reward delivery, or increase the airflow to clear the vapor from the chamber between responses.

Nicotine vapor self-administration

Consistent with vaping in humans, the vehicle group selfadministered similar amounts of vapor as the nicotine group in Experiment 2 [41]. Nicotine may produce an aversive reaction that limits its self-administration, but this aversive reaction is insufficient to prevent self-administration and the development of nicotine dependence [42]. In the present model, no classic discrimination between the active and inactive levers was observed in rats that administered nicotine vapor, which is usually seen in the intravenous model. Similarly, in a model of sufentanil vapor selfadministration, lever discrimination was not observed during short access $(1 \mathrm{~h})$ under a fixed-ratio 1 schedule [23]. Nicotine is much less reinforcing than sufentanil. Therefore, unsurprising was the lack of discrimination during short access $(1 \mathrm{~h})$ under a fixed-ratio 1 schedule with nicotine vapor in the present study. Altogether, these results suggest a difference in the discriminative stimulus effects of vaporized drugs of abuse relative to intravenous models. Even in models of intravenous self-administration, nicotine is a relatively mild reinforcer. To achieve robust lever and vehicle discrimination with nicotine self-administration in rats, training often requires food restriction, a higher fixed-ratio, long-access conditions, or intermittent sessions with periods of abstinence. The rats that self-administered nicotine had similar rates of lever discrimination compared with rats that self-administered vehicle. Lever discrimination was defined as obtaining $>50 \%$ vehicle (propylene glycol: glycerol)-containing puffs relative to total lever responses during the last 3 days of self-administration. These results suggest that the vehicle itself may have had some rewarding properties. Interestingly, in the nondiscriminator subpopulation of rats, rats that lever pressed for nicotine vapor pressed the inactive lever $\sim 2-3$ times more than the active. Further experiments are necessary to parse the mechanisms that underlie lever discrimination during vapor selfadministration. 
Pharmacological validation of nicotine vapor self-administration Varenicline significantly reduced nicotine vapor self-administration, with no effect on vehicle vapor self-administration. These results provide pharmacological evidence that nicotinic receptor activation mediates nicotine vaping behavior in rats. Varenicline also significantly reduced inactive lever responding in nicotineexposed rats but not in vehicle-exposed rats. These results are consistent with a previous study that reported that varenicline decreased inactive lever responding with intravenous nicotine self-administration [43]. No preclinical studies have evaluated the inhibitory effects of varenicline on electronic cigarette use, but these data suggest that varenicline may be an effective treatment [44]. Future studies are necessary to further validate its efficacy.

Mecamylamine-precipitated withdrawal after nicotine vapor selfadministration

Rats that self-administered nicotine vapor exhibited greater somatic signs of withdrawal and hyperalgesia following mecamylamine treatment in Experiment 4, with no effects in rats that selfadministered vehicle vapor. These results are consistent with previous studies that utilized passive nicotine vapor exposure $[20,45,46]$, passive subcutaneous nicotine delivery $[22,28,47]$, and intravenous nicotine self-administration in rodents [35, 48]. These results are also consistent with human data, in which electronic cigarette users reported symptoms of withdrawal, including irritability, nervousness, greater appetite, difficulty concentrating, depression, insomnia, and restlessness [49].

Nicotine vaping produced long-term anxiety-like behavior

In Experiment 5, rats that self-administered nicotine vapor exhibited an increase in anxiety-like behavior, reflected by the time spent on the open arms in the elevated plus maze, with no effect in rats that self-administered vehicle vapor. This measure was taken 3 weeks into protracted abstinence, suggesting that chronic electronic cigarette use produces long-lasting psychological effects. These results are translatable to clinical studies of human electronic cigarette users who reported an increase in anxiety during abstinence [49]. In the present study, the rats also exhibited an increase in drug-seeking behavior following reexposure to nicotine vapor-associated cues following protracted abstinence in Experiment 6, with no effect in the vehicle vapor group. These results suggest that chronic nicotine vapor selfadministration produces a long-lasting increase in nicotine craving that may have been mediated by an increase in anxiety-like behavior.

\section{Nicotine vaping produced long-term cardiac abnormalities}

Organ weight and dimensions are relatively simple measurements that are linked to toxicity, which are highly conserved across species [50]. Heart weight is known to correlate with hypertrophy, predict toxicity, and have little variability between subjects [51]. Passive nicotine exposure via subcutaneous minipumps (6 and 12 $\mathrm{mg} / \mathrm{kg} /$ day) decreased heart length and weight [31]. Significant decreases in heart, liver, kidney, brain, and thymus weights were also observed after chronic passive oral exposure to smokeless tobacco extracts $(0.75-3 \mathrm{mg} / \mathrm{ml}$ nicotine) [52]. However, these studies used the passive administration of relatively high doses of nicotine. The effects of nicotine vapor after the self-administration of low doses of nicotine on heart morphology are unknown. In Experiment 7 in the present study, rats that self-administered nicotine vapor exhibited decreases in heart length and weight compared with rats that self-administered vehicle vapor. These data are promising for the translational validity of the present model, given the known link between cigarette smoking and cardiovascular disease [53]. This preliminary evidence of the toxicity of nicotine vapor in a rodent self-administration procedure underscores the importance of conducting follow-up studies using more sophisticated histological analyses.
Nicotine vaping produced long-term pulmonary abnormalities In Experiment 8, rats that self-administered nicotine vapor also exhibited alveolar simplification in the lungs, with no effect in the vehicle vapor group or in rats that were acutely exposed to nicotine. Simplification of the lungs resembled the phenotype that was reported in previous studies of nicotine exposure in mice [54] and studies of chronic obstructive pulmonary disease (COPD) in humans [55]. In these studies, an increase in inflammation was also observed, which can drive alveolar simplification [56]. This result is supported by studies of the effects of passive nicotine vapor exposure on lung tissue, in which nicotine vapor significantly increased endothelial permeability, measured by electric cell-substrate impedance sensing [57]. This loss of endothelial barrier function was associated with oxidative stress and brisk inflammation. These data support recent studies of lung disease in adolescents who vaped electronic cigarettes [58] and recent deaths that were associated with electronic cigarette use [59]. Moreover, patients with COPD are more susceptible to bacterial and viral infections [60]. In a mouse model of passive electronic cigarette vapor exposure, pulmonary bacterial clearance following Streptococcus pneumonia infection significantly decreased compared with mice that were exposed to air [61]. In the same study, the immunological response to influenza $A$ virus infection was significantly impaired in electronic cigarette vaporexposed mice compared with controls. The present results suggest that nicotine vapor self-administration produces symptoms that are similar to COPD in rats and suggest that this model may be beneficial for developing new treatment strategies for bacterial and viral infections in electronic cigarette users.

Nicotine receptor dysregulation during protracted abstinence During protracted abstinence from nicotine vaping, we observed a decrease in $a 4$ and $\beta 2$ nicotinic acetylcholine receptor subunit gene expression in the nucleus accumbens and an increase in a3 nicotinic acetylcholine receptor subunit gene expression in the medial prefrontal cortex compared with vehicle controls (Fig. 6). Chronic nicotine use leads to the upregulation of nicotinic acetylcholine receptor binding sites in brain regions that modulate reward and stress in mice [62], rats [63], and humans [64]. This increase in nicotinic receptor binding sites is followed by a decrease during withdrawal [65], a pattern that follows the establishment of nicotine dependence and the sensitivity to nicotine [66]. However, most studies reported no changes in nicotinic acetylcholine receptor mRNA levels, suggesting that chronic nicotine only dysregulates nicotinic acetylcholine receptors at the posttranscriptional level. In contrast, the present study found that 3 weeks of abstinence from nicotine vaping decreased $a 4$ and $\beta 2$ nicotinic acetylcholine receptor subunit gene expression in the nucleus accumbens and increased a3 nicotinic acetylcholine receptor subunit gene expression in the medial prefrontal cortex compared with vehicle controls. Previous studies found no brain-wide changes in nicotinic acetylcholine receptor mRNA levels in nicotine-dependent rats, but most of these studies investigated only early withdrawal or evaluated animals under steady-state nicotine treatment conditions. Some studies reported region-specific changes, including localized decreases in $\beta 2$ nicotinic acetylcholine receptor mRNA levels in nicotine-dependent mice under steady-state nicotine treatment conditions [67]. Other studies found that 4 weeks of abstinence from gestational exposure to nicotine was associated with a decrease in a4 nicotinic acetylcholine receptor expression in the VTA and an increase in a3 nicotinic acetylcholine receptor expression in the nucleus accumbens core, further suggesting that chronic nicotine use may change nicotinic acetylcholine receptor mRNA levels in a region-, time-, and subunit-specific manner [68]. Nicotine dependence is thought to be primarily mediated by a4 $\beta 2$ nicotinic acetylcholine receptors [69]. The downregulation of $\alpha 4$ and $\beta 2$ nicotinic acetylcholine receptor subunits during protracted abstinence may contribute to pain-, anxiety-, and relapse-like behaviors 
that are observed at this timepoint. The $a 5 / a 3 / \beta 4$ nicotinic acetylcholine receptor subunit gene cluster has been shown to play a role in nicotine dependence liability [70]. The upregulation of a3 nicotinic acetylcholine receptor subunits during protracted abstinence may have also contributed to withdrawal-like behaviors that were observed in the present study.

\section{Limitations}

We did not observe differences in lever pressing between nicotine vapor self-administration and vehicle vapor self-administration. Higher levels of oral and intravenous drug self-administration are commonly observed compared with water and saline self-administration, but such discrimination has been difficult to observe using vapor self-administration of drugs of abuse, such as $\Delta^{9}$-tetrahydrocannabinol and sufentanil [23, 71]. Discrimination is easier to observe when more challenging response requirements are employed (e.g., higher fixed-ratio and progressive-ratio requirements) [71]. One potential explanation for the lack of discrimination in the present study is the potential reinforcing effect of the vehicle itself $(1: 1$, propylene glycol:glycerol), which has a sweet taste and is also reinforcing in humans. Many electronic cigarette users consume propylene glycol and glycerol mixtures without nicotine [41]. Future studies should take the reinforcing properties of the vehicle into account. We also did not track the estrous cycle in female rats to determine its possible effects on behavior and nicotine metabolism. We only measured somatic symptoms of withdrawal after mecamylamine administration. Therefore, further studies should evaluate the effect of spontaneous withdrawal and the sensitivity to mecamylamine in the absence of nicotine exposure. The liquid solutions that were used in the present study consisted of pure nicotine $(>99.9 \%$, Sigma) and pure propylene glycol and glycerol (>99\%, Sigma). The effects that were observed in the lungs may have been attributable to possible impurities in the liquid composition upon combustion. Finally, the relatively small sample size that was used in the nicotinic acetylcholine receptor subunit experiment may have led to an inflated effect size. Future studies are needed to confirm these results.

\section{CONCLUSION}

Altogether, the present findings validate a model of nicotine vapor self-administration in rats based on measures that are relevant to nicotine dependence and electronic cigarette use in humans. Three weeks of daily $(1 \mathrm{~h})$ nicotine vapor self-administration in rats did not lead to discrimination between nicotine and vehicle vapor or between active and inactive lever responses, but it produced robust symptoms of nicotine dependence and addiction-related behaviors, caused lung and heart abnormalities, and altered nicotinic acetylcholine receptor subunit mRNA expression in the brain. These results underscore the importance of studying the long-term behavioral and health effects of electronic cigarette use.

\section{FUNDING AND DISCLOSURE}

This work was supported by the National Institute on Drug Abuse (grant no. 1F31DA047113-01 to LCS and grant no. DA036691 to OG), National Institute on Alcohol Abuse and Alcoholism (grant no. AA022977 and AA006420 to OG), Tobacco-Related Disease Research Program (grant no. 27IR-0047 to OG), and National Research Fund-Flanders (postdoctoral fellowship to LLGC). The authors declare no competing interests.

\section{DATA AND MATERIAL AVAILABILITY}

All data are available in the main text or in Supplementary Material.

\section{ACKNOWLEDGEMENTS}

The authors thank Michael Arends for proofreading the manuscript.

\section{AUTHOR CONTRIBUTIONS}

MKa and OG designed the vapor self-administration experiment. GdG and MKI built the vapor self-administration chambers. LCS, SS, and LT performed the self-administration experiments. LCS, NV, and LT performed the behavioral experiments. LCS, GdG, JB, and YS harvested the organs. XS designed the pulmonary dysfunction experiment. AJ performed the tissue analysis. KS performed the receptor subunit experiments. LCS, LLGC, and MKa analyzed the data. LCS generated the figures. LCS prepared the manuscript and Supplementary Material. MKa and OG edited the manuscript and Supplementary Material. All of the authors reviewed the final version of the manuscript.

\section{ADDITIONAL INFORMATION}

Supplementary Information accompanies this paper at (https://doi.org/10.1038/ s41386-020-0734-8).

Publisher's note Springer Nature remains neutral with regard to jurisdictional claims in published maps and institutional affiliations.

\section{REFERENCES}

1. Services UDOHAH. E-cigarette use among youth and young adults: a report of the surgeon general. Atlanta, GA: US Department of Health and Human Services; 2016.

2. Luxton NA, Shih P, Rahman MA, Electronic cigarettes and smoking cessation in the perioperative period of cardiothoracic surgery: views of australian clinicians. Int J Environ Res Public Health. 2018;15:11.

3. Fong GT, Elton-Marshall T, Driezen P, Kaufman AR, Cummings KM, Choi K. et al. U.S. adult perceptions of the harmfulness of tobacco products: descriptive findings from the 2013-14 baseline wave 1 of the path study. Addict Behav. 2019;91:180-7.

4. Mathur A, Dempsey OJ. Electronic cigarettes: a brief update. J R Coll Physicians Edinb. 2018;48:346-51.

5. Mead EL, Duffy V, Oncken C, Litt MD. E-cigarette palatability in smokers as a function of flavorings, nicotine content and propylthiouracil (PROP) taster phenotype. Addict Behav. 2019;91:37-44.

6. Takahashi $Y$, Kanemaru $Y$, Fukushima T, Eguchi K, Yoshida S, Miller-Holt J. et al. Chemical analysis and in vitro toxicological evaluation of aerosol from a novel tobacco vapor product: a comparison with cigarette smoke. Regul Toxicol Pharm. 2018;92:94-103.

7. Taylor M, Carr T, Oke O, Jaunky T, Breheny D, Lowe F. et al. E-cigarette aerosols induce lower oxidative stress in vitro when compared to tobacco smoke. Toxicol Mech Methods. 2016;26:465-76.

8. Sifat AE, Vaidya B, Kaisar MA, Cucullo L, Abbruscato TJ. Nicotine and electronic cigarette (E-Cig) exposure decreases brain glucose utilization in ischemic stroke. J Neurochem. 2018;147:204-21.

9. Shen Y, Wolkowicz MJ, Kotova T, Fan L, Timko MP. Transcriptome sequencing reveals e-cigarette vapor and mainstream-smoke from tobacco cigarettes activate different gene expression profiles in human bronchial epithelial cells. Sci Rep. 2016;6:23984.

10. Rankin GD, Wingfors H, Uski O, Hedman L, Ekstrand-Hammarstrom B, Bosson J. et al. The toxic potential of a fourth-generation E-cigarette on human lung cell lines and tissue explants. J Appl Toxicol. 2019;39:1143-54.

11. Zagoriti Z, El Mubarak MA, Farsalinos K, Topouzis S. Effects of exposure to tobacco cigarette, electronic cigarette and heated tobacco product on adipocyte survival and differentiation in vitro. Toxics. 2020;8:9.

12. Welz C, Canis M, Schwenk-Zieger S, Becker S, Stucke V, Ihler F. et al. Cytotoxic and genotoxic effects of electronic cigarette liquids on human mucosal tissue cultures of the oropharynx. J Environ Pathol Toxicol Oncol. 2016;35:343-54.

13. Cohen A, George O. Animal models of nicotine exposure: relevance to secondhand smoking, electronic cigarette use, and compulsive smoking. Front Psychiatry. 2013;4:41.

14. Erku DA, Gartner CE, Do JT, Morphett K, Steadman KJ. Electronic nicotine delivery systems (e-cigarettes) as a smoking cessation aid: a survey among pharmacy staff in Queensland, Australia. Addict Behav. 2019;91:227-33.

15. Filippidis FT, Laverty AA, Mons U, Jimenez-Ruiz C, Vardavas $\mathrm{Cl}$. Changes in smoking cessation assistance in the European Union between 2012 and 2017: pharmacotherapy versus counselling versus e-cigarettes. Tob Control. 2019;28:95-100.

16. Donny EC, Caggiula AR, Mielke MM, Jacobs KS, Rose C, Sved AF. Acquisition of nicotine self-administration in rats: the effects of dose, feeding schedule, and drug contingency. Psychopharmacology. 1998;136:83-90.

17. Belluzzi JD, Wang R, Leslie FM. Acetaldehyde enhances acquisition of nicotine selfadministration in adolescent rats. Neuropsychopharmacology. 2005;30:705-12.

18. Jensen RP, Luo W, Pankow JF, Strongin RM, Peyton DH. Hidden formaldehyde in e-cigarette aerosols. N Engl J Med. 2015;372:392-4. 
19. El-Hellani A, Al-Moussawi S, El-Hage R, Talih S, Salman R, Shihadeh A. et al. Carbon monoxide and small hydrocarbon emissions from sub-ohm electronic cigarettes. Chem Res Toxicol. 2019;32:312-7.

20. Kallupi M, George O. Nicotine vapor method to induce nicotine dependence in rodents. Curr Protoc Neurosci. 2017;80:84141-484110.

21. Gilpin NW, Whitaker AM, Baynes B, Abdel AY, Weil MT, George O. Nicotine vapor inhalation escalates nicotine self-administration. Addict Biol. 2014;19:587-92.

22. Malin DH, Lake JR, Carter VA, Cunningham JS, Hebert KM, Conrad DL. et al. The nicotinic antagonist mecamylamine precipitates nicotine abstinence syndrome in the rat. Psychopharmacology. 1994;115:180-4.

23. Vendruscolo JCM, Tunstall BJ, Carmack SA, Schmeichel BE, Lowery-Gionta EG, Cole $M$. et al. Compulsive-like sufentanil vapor self-administration in rats. Neuropsychopharmacology. 2018:43:801-9.

24. Hiler M, Breland A, Spindle T, Maloney S, Lipato T, Karaoghlanian N. et al. Electronic cigarette user plasma nicotine concentration, puff topography, heart rate, and subjective effects: Influence of liquid nicotine concentration and user experience. Exp Clin Psychopharmacol. 2017;25:380-92.

25. Vansickel AR, Edmiston JS, Liang Q, Duhon C, Connell C, Bennett D. et al. Characterization of puff topography of a prototype electronic cigarette in adult exclusive cigarette smokers and adult exclusive electronic cigarette users. Regul Toxicol Pharm. 2018;98:250-6.

26. Russell MA, Feyerabend $C$, Cole PV. Plasma nicotine levels after cigarette smoking and chewing nicotine gum. Br Med J. 1976;1:1043-6.

27. Farsalinos KE, Spyrou A, Tsimopoulou K, Stefopoulos C, Romagna G, Voudris V. Nicotine absorption from electronic cigarette use: comparison between first and new-generation devices. Sci Rep. 2014;4:4133.

28. Malin DH, Lake JR, Newlin-Maultsby P, Roberts LK, Lanier JG, Carter VA. et al. Rodent model of nicotine abstinence syndrome. Pharm Biochem Behav. 1992;43:779-84

29. George O, Grieder TE, Cole M, Koob GF. Exposure to chronic intermittent nicotine vapor induces nicotine dependence. Pharm Biochem Behav. 2010;96:104-107.

30. Pellow S, Chopin P, File SE, Briley M. Validation of open:closed arm entries in an elevated plus-maze as a measure of anxiety in the rat. J Neurosci Methods. 1985;14:149-67.

31. Elliott BM, Faraday MM, Grunberg NE. Effects of nicotine on heart dimensions and blood volume in male and female rats. Nicotine Tob Res. 2003;5:341-8.

32. Gourlay SG, Benowitz NL. Arteriovenous differences in plasma concentration of nicotine and catecholamines and related cardiovascular effects after smoking, nicotine nasal spray, and intravenous nicotine. Clin Pharmacol Therapeutics. 1997;62:453-63.

33. Shoaib M, Stolerman IP. Plasma nicotine and cotinine levels following intravenous nicotine self-administration in rats. Psychopharmacology. 1999;143:318-21.

34. Miller RP, Rotenberg KS, Adir J. Effect of dose on the pharmacokinetics of intravenous nicotine in the rat. Drug Metab Dispos. 1977:5:436-43.

35. Cohen A, Treweek J, Edwards S, Leao RM, Schulteis G, Koob GF. et al. Extended access to nicotine leads to a CRF1 receptor dependent increase in anxiety-like behavior and hyperalgesia in rats. Addict Biol. 2015;20:56-68.

36. Valentine JD, Hokanson JS, Matta SG, Sharp BM. Self-administration in rats allowed unlimited access to nicotine. Psychopharmacology. 1997;133:300-4.

37. Donny EC, Caggiula AR, Rowell PP, Gharib MA, Maldovan V, Booth S. et al. Nicotine self-administration in rats: estrous cycle effects, sex differences and nicotinic receptor binding. Psychopharmacology. 2000;151:392-405.

38. Rosenzweig-Lipson S, Thomas S, Barrett JE. Attenuation of the locomotor activating effects of D-amphetamine, cocaine, and scopolamine by potassium channel modulators. Prog Neuropsychopharmacol Biol Psychiatry. 1997;21:853-72.

39. Corrigall WA, Coen KM. Nicotine maintains robust self-administration in rats on a limited-access schedule. Psychopharmacology. 1989:99:473-8.

40. Fudala PJ, Iwamoto ET. Further studies on nicotine-induced conditioned place preference in the rat. Pharm Biochem Behav. 1986;25:1041-9.

41. Morean ME, Kong G, Cavallo DA, Camenga DR, Krishnan-Sarin S. Nicotine concentration of e-cigarettes used by adolescents. Drug Alcohol Depend. 2016;167:224-7.

42. Henningfield JE, Goldberg SR. Nicotine as a reinforcer in human subjects and laboratory animals. Pharm Biochem Behav. 1983;19:989-92.

43. George O, Lloyd A, Carroll FI, Damaj MI, Koob GF. Varenicline blocks nicotine intake in rats with extended access to nicotine self-administration. Psychopharmacology. 2011;213:715-22.

44. Coe JW, Brooks PR, Vetelino MG, Wirtz MC, Arnold EP, Huang J. et al. Varenicline: an alpha4beta2 nicotinic receptor partial agonist for smoking cessation. J Med Chem. 2005;48:3474-7.

45. Baiamonte BA, Valenza M, Roltsch EA, Whitaker AM, Baynes BB, Sabino V. et al. Nicotine dependence produces hyperalgesia: role of corticotropin-releasing factor-1 receptors (CRF1Rs) in the central amygdala (CeA). Neuropharmacology. 2014;77:217-23.
46. Kallupi M, de Guglielmo G, Larrosa E, George O. Exposure to passive nicotine vapor in male adolescent rats produces a withdrawal-like state and facilitates nicotine self-administration during adulthood. Eur Neuropsychopharmacol. 2019;29:1227-34.

47. Damaj MI, Kao W, Martin BR. Characterization of spontaneous and precipitated nicotine withdrawal in the mouse. J Pharmacol Exp therapeutics. 2003;307:526-34

48. Paterson NE, Markou A. Prolonged nicotine dependence associated with extended access to nicotine self-administration in rats. Psychopharmacology. 2004;173:64-72.

49. Hughes JR, Peters EN, Callas PW, Peasley-Miklus C, Oga E, Etter JF. et al. Withdrawal symptoms from e-cigarette abstinence among former smokers: a pre-post clinical trial. Nicotine Tob Res. 2019;22:734-9.

50. Bailey SA, Zidell RH, Perry RW. Relationships between organ weight and body/ brain weight in the rat: what is the best analytical endpoint? Toxicol Pathol. 2004;32:448-66.

51. Michael B, Yano B, Sellers RS, Perry R, Morton D, Roome N. et al. Evaluation of organ weights for rodent and non-rodent toxicity studies: a review of regulatory guidelines and a survey of current practices. Toxicol Pathol. 2007;35:742-50.

52. Yu C, Zhang Z, Liu Y, Zong Y, Chen Y, Du X. et al. Toxicity of smokeless tobacco extract after 184-day repeated oral administration in rats. Int J Environ Res Public Health. 2016;13:281.

53. Ambrose JA, Barua RS. The pathophysiology of cigarette smoking and cardiovascular disease: an update. J Am Coll Cardiol. 2004;43:1731-7.

54. Garcia-Arcos I, Geraghty P, Baumlin N, Campos M, Dabo AJ, Jundi B, et al. Chronic electronic cigarette exposure in mice induces features of COPD in a nicotinedependent manner. Thorax. 2016;71:1119-29.

55. Anderson AE Jr., Hernandez JA, Eckert $P$, Foraker AG. Emphysema in lung macrosections correlated with smoking habits. Science. 1964;144:1025-6.

56. Branchfield K, Nantie L, Verheyden JM, Sui P, Wienhold MD, Sun X. Pulmonary neuroendocrine cells function as airway sensors to control lung immune response. Science. 2016;351:707-10.

57. Schweitzer KS, Chen SX, Law S, Van Demark M, Poirier C, Justice MJ. et al. Endothelial disruptive proinflammatory effects of nicotine and e-cigarette vapor exposures. Am J Physiol Lung Cell Mol Physiol. 2015;309:L175-87.

58. McConnell R, Barrington-Trimis JL, Wang K, Urman R, Hong $\mathrm{H}$, Unger J. et al. Electronic cigarette use and respiratory symptoms in adolescents. Am J Respir Crit Care Med. 2017;195:1043-9.

59. Ledford H. Scientists chase cause of mysterious vaping illness as death toll rises. Nature. 2019;574:303-4.

60. Leung JM, Tiew PY, Mac Aogain M, Budden KF, Yong VF, Thomas SS. et al. Pethe $\mathrm{K}$, Hansbro PM, Chotirmall SH. The role of acute and chronic respiratory colonization and infections in the pathogenesis of COPD. Respirology. 2017;22:634-50.

61. Sussan TE, Gajghate S, Thimmulappa RK, Ma J, Kim JH, Sudini K. et al. Exposure to electronic cigarettes impairs pulmonary anti-bacterial and anti-viral defenses in a mouse model. PLoS ONE. 2015;10:e0116861.

62. Marks MJ, Burch JB, Collins AC. Effects of chronic nicotine infusion on tolerance development and nicotinic receptors. J Pharmacol Exp therapeutics. 1983;226:817-25.

63. Schwartz RD, Kellar KJ. Nicotinic cholinergic receptor binding sites in the brain regulation in vivo. Science. 1983;220:214-6.

64. Benwell ME, Balfour DJ, Anderson JM. Evidence that tobacco smoking increases the density of $(-)-[3 \mathrm{H}]$ nicotine binding sites in human brain. J Neurochem. 1988;50:1243-7.

65. Marks MJ, Stitzel JA, Collins AC. Time course study of the effects of chronic nicotine infusion on drug response and brain receptors. J Pharmacol Exp therapeutics. 1985;235:619-28.

66. Markou A. Review. Neurobiology of nicotine dependence. Philos Trans R Soc Lond B Biol Sci. 2008;363:3159-68.

67. Marks MJ, Pauly JR, Gross SD, Deneris ES, Hermans-Borgmeyer I, Heinemann SF. et al. Nicotine binding and nicotinic receptor subunit RNA after chronic nicotine treatment. J Neurosci. 1992;12:2765-84.

68. Chen H, Parker SL, Matta SG, Sharp BM. Gestational nicotine exposure reduces nicotinic cholinergic receptor ( $\mathrm{nAChR}$ ) expression in dopaminergic brain regions of adolescent rats. Eur J Neurosci. 2005;22:380-8.

69. Picciotto MR, Kenny PJ. Molecular mechanisms underlying behaviors related to nicotine addiction. Cold Spring Harb Perspect Med. 2013;3:a012112.

70. Improgo MR, Scofield MD, Tapper AR, Gardner PD. The nicotinic acetylcholine receptor CHRNA5/A3/B4 gene cluster: dual role in nicotine addiction and lung cancer. Prog Neurobiol. 2010;92:212-26.

71. Freels TG, Baxter-Potter LN, Lugo JM, Glodosky NC, Wright HR, Baglot SL. et al. Vaporized cannabis extracts have reinforcing properties and support conditioned drug-seeking behavior in rats. J Neurosci. 2020;40:1897-908. 